\title{
The Research on China Export Trade in Cultural Goods
}

\author{
Yueling Xiao \\ Shanghai University, No.99 Shangda Road, Shanghai City, P.R. China \\ 18217667634@163.com
}

Keywords: Cultural goods; Bilateral cultural trade; Cultural distance; Gravity model

\begin{abstract}
China cultural goods trade is attracting wide attention from all walks of life. But there are still plenty of problems behind the rapid development. Therefore, this article studies China cultural goods trade from two perspectives, analysis of situation and the empirical analysis. In the empirical analysis, the extended gravity model is adopted. The results show that $\mathrm{R}^{2}$ of the model is 0.96 , which shows the fitting effect of the equation is better, and most of the explanatory variables are significant. Then, we can draw the following conclusions: The structure of Chinese cultural goods trade is imbalance, China cultural goods exports are mainly concentrated in the visual arts and crafts. Cultural factors such as cultural distance and addiction in cultural goods consumption have a significant impact on the export of cultural goods.
\end{abstract}

\section{Introduction}

With the advent of the era of globalization, knowledge and information, production and trade of cultural goods gradually expanded. In the last decade, governments pay more and more attention to the rapid development of cultural trade, at the same time, many scholars try to research on cultural trade issues.

Marvasti's article (1994) is one of the earliest representative literature of cultural goods trade empirical research field, its most important contribution and advantage is that it tests some cultural factors impact on cultural goods trade such as the lack of intellectual property rights, language, religion, trade restrictions [1]. Schulze's groundbreaking in 1999 is giving a clear definition and classification of cultural goods, especially the art, and also verify the new trade theory is not suitable for art trade. He uses the original gravity model to analyze the cultural trade data from 1990 to 1994 about the 49 kinds of art which cannot be copied. The results found that the language similarity has a large effect on the promotion of cultural trade [2]. White and Tadesse (2010) began to take this important factor of cultural distance into the historical studies of cultural trade, and on the basis of the original document, they created cultural distance calculation formula, and also introduces the factors of migration. Since then, the researches on influencing factors of cultural trade have became more and more concrete [3]. Qu Xiaoru and Han Lili (2011) use bilateral cultural trade data as sample from 1992 to 2009 between China and the other 41 countries and regions. Through the "expansion of gravity model", they use "cultural distance" of cultural trade impact of empirical test shows that cultural distance on the cultural goods trade flows has significant negative effects, and the larger "cultural distance" between the trade partners will hinder China's cultural goods exports [4].

The study of cultural trade is mainly divided into the qualitative analysis and the empirical analysis. Qualitative analysis is mostly focused on trade theory to analyze the current situation of cultural trade and the existing problems. In the case of empirical analysis, the main method is to use gravity model, and extend the traditional gravity model by adding different explanatory variables. Different scholars may choose to interpret variables in different ways, or use different sources of data, or take different ways of processing. Thus, the conclusions are not quite the same. So there is still a lot of work to be done on the cultural trade filed in the future. 


\section{Status Analysis about China Cultural Goods Export Trade}

This paper analyzes the trade of Chinese culture goods from the perspective of the world and the trading partners. About the research on cultural trade influence factors, this paper mainly uses the bilateral trade flows between China and trading partners to analyze the influence factors of cultural goods export trade in China [5,6].

First of all, the paper analyzes the present situation and existing problems of the development of China cultural goods from the perspective of the total export in China cultural goods to the world. From 1992 to 2014, the scale of export of cultural goods increased by 43.5 times. The development of cultural trade as an important part of the revitalization of the cultural industry and the transformation of the way of foreign trade development, has effectively promoted the pace of "going out" of China culture.

The bar graph in Fig. 1 shows the value of export in China cultural goods from 1992 to 2014. As you can see from Fig. 1, the export of Chinese cultural goods is increasing year by year. The data source is UN comtrade database. Before 2001, the export of cultural goods increased steadily, and its values were small. In 2001, after China joined the WTO, exports of cultural goods increased even more rapidly. There are two reasons. On the one hand, after joining the WTO, trade liberalization has increased, leading to a rapidly increase in overall trade value, and the boom development of cultural industry. On the other hand, China's overall national strength has been strengthened, and China culture has received more and more recognition around the world, which promoted the export of cultural trade [7].

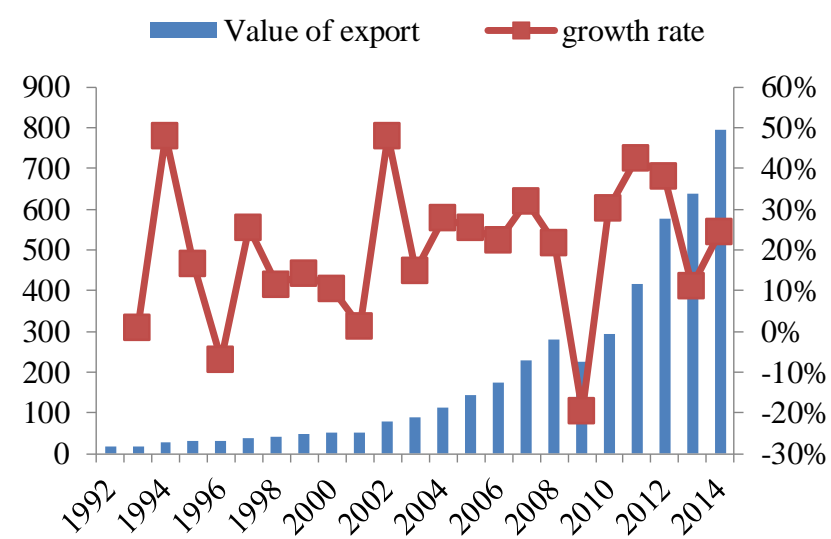

Figure 1. Value of export [billion \$] and growth rate[\%]

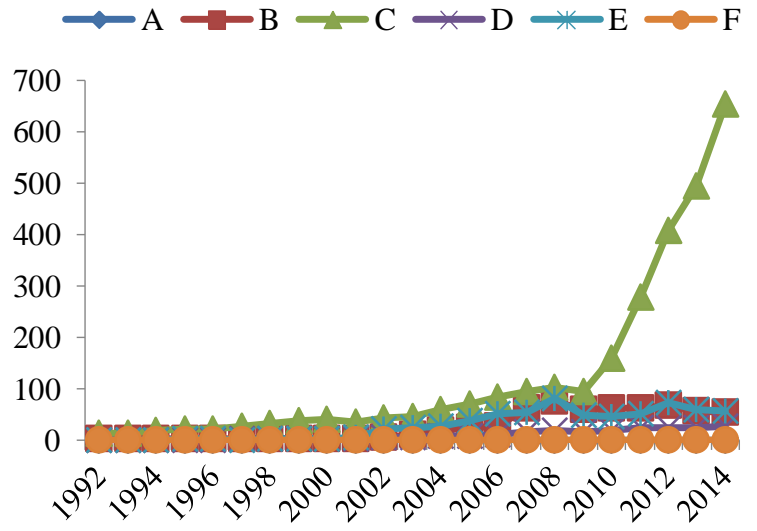

Figure 2. Value of export of 6 kinds of cultural goods [billion $\$$ ]

In 2009, the value of cultural exports fell, closely related to the global financial crisis of 2008 . After the financial crisis, the global economic situation was grim, no exception in China. But since 2010, the economy has recovered, the cultural industry has grown rapidly, with the strong support of national policies, exports have been growing.

The line chart in Fig. 1 shows the growth rate of China cultural goods exports. As you can see from the chart, the growth rate of most years is positive, between $20 \%$ and $40 \%$. There were three periods of rapid growth, in 1994, 2002, and 2011, at nearly 50\%. The fiscal, taxation, financial, foreign exchange and other institutional reform measures introduced in 1994 went smoothly and effectively promoted the healthy development of the national economy. This may be an important reason for the rise in cultural exports in 1994. The most important reason for the high growth in 2002 was China's accession to the WTO in 2001, which contributed greatly to China's economic and trade growth, as well as cultural trade. The high growth in 2011 was partly due to the high growth of Chinese cultural exports after the financial crisis of 2008, when the global economy rebounded. Another part of the reason is that the government pays more and more attention to culture industry, and introduced relevant policies and measures, provides a good policy support for the development of cultural industry. Thus, the cultural goods exports also greatly increased. 
Fig. 2 shows the export of six major Chinese cultural goods from 1992 to 2014. In this paper, we use international trade of cultural goods and services defined with the Harmonised System (HS) 2007 codes. We mainly focus on cultural goods, which can be grouped under the following headings: A. Cultural and Natural Heritage; B. Performance and Celebration; C. Visual Arts and Crafts; D. Books and Press; E. Audio-visual and Interactive Media; F. Design and Creative Services. Fig. 2 shows that the export value in visual arts and crafts is the largest, and after 2009, visual arts and crafts contribute to the most part of cultural goods export growth. Second is performance and celebration and audio-visual and interactive media. Third is books and Press. The least is cultural and natural heritage and design and creative services.

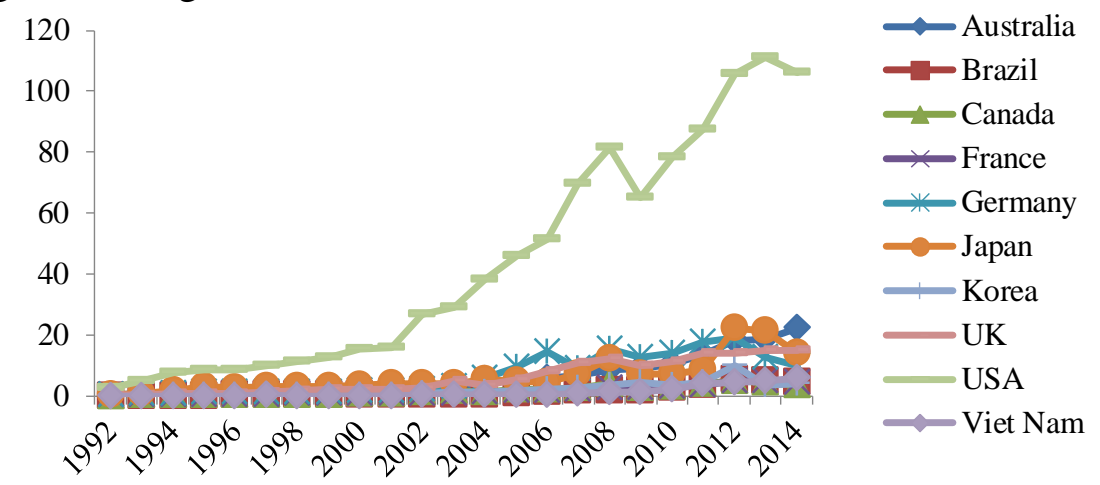

Figure 3. Bilateral Cultural Goods Trade Value [billions \$]

Comprehensive consideration of trade relations, cultural factors, etc., we select 10 major trading partners around the world, and analyze the bilateral cultural trade. The 10 trade partners are Australia, Brazil, Canada, France, Germany, Japan, South Korea, UK, USA and Vietnam. As you can see from figure 3, China exports the largest amount of cultural goods to USA, followed by Australia, Britain, Japan and Germany. Finally, Vietnam, Brazil, France, South Korea, Canada.

\section{Empirical Analysis}

Economists normally use the gravity model to discuss bilateral trade flows between countries. Since the $1960 \mathrm{~s}$, the gravity model has been involved in the study of international trade empirical studies, which have got a considerable success. Therefore, in this article, we set a gravity model, and we will firstly introduce the control variables such as GDP and geographic distance between China and its trade partners.

Cultural products trade is belong to the high demand after the basic living requirement, needs certain income level support. The need for spiritual life becomes higher and higher after the material standard of living reaches a certain level. Gross domestic product (GDP) is the characterization of income, is an important index of a country's economic size. So we expect that the larger economies, the underlying cultural goods and services have the greater demand and supply ability.

We hypothesize that the lager distant of the geographical distance, the greater the transaction costs of cultural trade. Therefore, the geographic distance is inversely proportional to the trade flows of bilateral cultural goods. In addition to the control variables of the gravity model above, we will also consider the following factors [8]:

The first one is the gap of per capital purchasing power. It represents a gap in the level of consumption between China and trade partners. The per capita purchasing power of both countries is likely to be either positively correlated or negatively correlated with the trade of cultural goods in both countries. On the one hand, consumers of similar purchasing power may result in a similar preference for consumer demand, thus promoting the development of trade between the two countries' horizontal cultural goods. On the other hand, the increase in purchasing power is a 
reflection of the different comparative advantages and factors endowments of the two countries, which promoted the trade of vertical cultural goods in the two countries. In this article, with the per capita of difference between China and trading partners on behalf of the gap of per capital purchasing power. To eliminate the influence of the absolute size deviation, this article carried out the relative difference index method, formula is as follows:

$\mathrm{PGDPD}_{\mathrm{ij}}=1+[\mathrm{W} \ln \mathrm{W}+(1-\mathrm{W}) \ln (1-\mathrm{W})] / \ln 2$

In Eq. $1, \mathrm{~W}=\mathrm{PGDP}_{\mathrm{i}} /\left(\mathrm{PGDP}_{\mathrm{i}}+\mathrm{PGDP}_{\mathrm{j}}\right), \mathrm{PGDP}_{\mathrm{i}}$ and $\mathrm{PGDP}_{\mathrm{j}}$ represent per GDP of China and per GDP of China's cultural trade partners respectively.

The second one is the cultural distance. This variable is used to measure the psychological distance between the two countries' differences in preferences, customs, values and moral values. We expect that the increasing cultural distance between countries have a positive impact on cultural goods trade. Because the greater the cultural gap is, the easier it will be for consumers to spend on it [9].

The third one is addiction in cultural goods consumption, in other words, the consumer for a continuous dependence and consumption of cultural goods, such as a preference for certain types of music, a style movie appreciation, etc., which will not only continue to increase this familiar cultural goods consumption, but also to exclude other alternative cultural goods. This is one of the most important characteristics of cultural products as well. In this article, we use the lag issue of bilateral cultural goods trade as a variable of addiction in cultural goods consumption.

The last one is bilateral network coverage of science and technology. With the rise of the Internet, the consumption of cultural goods and service gradually improve the requirement of science and technology application ability. The Internet as the most important way to spread cultural goods, is the bridge of international cultural communication. The penetration rate is higher, the more chance to get to know a different national culture, the wider the cultural goods spread, the more frequently the culture communication is. In addition, cultural goods and services can also be through online publicity, online ordering, online experience way to interact with the consumers, so high-tech countries resident to enjoy conditionally to high-tech products as the carrier of culture. As a result, countries with higher levels of Internet technology should have greater demand for cultural goods and cultural services, and the greater the scale of cultural trade.

Based on the above factors, the gravity model of this article is established as follows [10,11]:

$\ln X=\beta_{0}+\beta_{1} \ln$ GDP $+\beta_{2} \ln$ PGDPD $+\beta_{3} \ln$ Dist $+\beta_{4} \ln c$ Dist $+\beta_{5} \ln \mathrm{X}_{-1}+\beta_{6} \ln$ ICT $+\mu(2)$

In Eq. 2, $X$ represents the export volume of bilateral cultural goods of China and its trade partners; GDP is the GDP of trade partners; PGDPD means the gap of per capital purchasing power of China and its trade partners. Dist shows the geographic distance between China and its trade partners; cDist says the cultural distance between China and its trade partners; The $\mathrm{X}_{-1}$ represents a lag in bilateral cultural goods trade, which measures the addiction in cultural goods consumption. ICT represents the extent of bilateral network coverage of science and technology between China and its trade partners.

Firstly, we conduct Hausman test of the model, and the results show that it is reasonable to return to the random effect model. Due to only using the bilateral cultural goods trade data of China and Australia, Brazil, Canada, France, Germany, Japan, South Korea, UK, USA and Vietnam, when the samples from the overall random sampling, random effect model can be used to explain the overall statistical properties. Therefore, setting the model for the random effect model is more reasonable, and the regression with random effects can be ideally needed to determine the conclusions [12]. 
Table 1 The result of regression

\begin{tabular}{c|cccccc}
\hline Variables & $\operatorname{lnGDP}$ & $\operatorname{lnPGDPD}$ & $\operatorname{lnDist}$ & $\operatorname{lncDist}$ & $\ln \mathrm{X}_{-1}$ & $\operatorname{lnICT}$ \\
\hline \multirow{2}{*}{ Regression } & $0.081^{* *}$ & $0.021^{* *}$ & $-0.008^{*}$ & $0.105^{* *}$ & $0.879^{* * *}$ & $0.004^{*}$ \\
& $(0.036)$ & $(0.008)$ & $(0.061)$ & $(0.026)$ & $(0.031)$ & $(0.028)$ \\
\hline & & & \multicolumn{2}{c}{$\mathrm{R}^{2}=0.9603$} & \multicolumn{2}{c}{ Number of obs: 220}
\end{tabular}

Note: The brackets below the coefficients are the robust standard error, $* * *, * * *$, respectively, represent the significant levels of $10 \%, 5 \%$, and $1 \%$.

From the regression results in Table 1, the explanatory variables of the gravity model are consistent with the existing literature on the positive and negative effects of bilateral trade in Chinese cultural good. Then we can get some conclusions from the regression results as follows: Increase of trade partners' GDP promotes the imports in China culture goods. It may be the reason that the trade partners' GDP would increase the demand for cultural goods, so the import of cultural goods increases. The coefficient of the gap of per capital purchasing power is positive. It indicates that China and its trade partners per capital purchasing power have bigger difference, so it promotes the development of vertical cultural goods trade between the two countries. The trade in cultural goods is similar to the general goods trade, which is affected by the cost of trade, and the further the geographical distance, the higher the transportation costs. Therefore, the export of Chinese cultural goods is negatively correlated with geographical distance variables. The cultural distance is a measure of the distance between the two cultures, and the greater the cultural gap, the easier it will be for consumers to spend. The coefficient of addiction in cultural goods consumption is positive, and the largest of the six explanatory variables. It indicates that consumption addiction has a greater impact on the export of Chinese cultural goods. This is an indirect indication of the growing acceptance of Chinese culture by trade partners. The bilateral network coverage of science and technology between China and trade partners can lower the matching cost and transaction cost of bilateral trade. From the point of regression results, the higher level of bilateral network coverage of science and technology has a promoting effect on bilateral cultural goods exports. However, it is not very obvious in this article.

The $\mathrm{R}^{2}$ of the model is 0.96, which shows the fitting effect of the equation is better. Addiction in cultural goods consumption is significantly under $1 \%$ significance level, and geographic distance and bilateral network coverage of science and technology are significantly under $10 \%$ significance level, the rest of the explanatory variables are significant under 5\% significance level.

\section{Conclusion}

Using data for the period 1993-2014, covering 10 trade partners of China and a number of cultural goods, we estimate a gravity equation. The consumption of cultural goods is shown to be addictive.

The trade structure of Chinese cultural goods is unbalanced. China's cultural goods exports are mainly concentrated in the visual arts and crafts, and the cultural connotation of printed matter and the unique cultural heritage and the performing arts exports is small. It determines the Chinese cultural goods trade of the huge surplus with the nature of trade in goods. Even if there is a huge cultural goods surplus, it will not have a huge impact on Chinese culture connotation output. Therefore, there may be a huge "cultural discount" when Chinese cultural goods enter the western market. So if we want to understand the overseas audience's consumption habits and aesthetic temperament and interest in cultural goods, produce the cultural goods to the overseas customers easy to understand, accept and appreciate, realize the spread of modern fusion of cultural diversity and nationality, and import the advanced technology to deduce, can effectively reduce the "cultural discount", reduce the ideological barriers. This is the key of the development of foreign cultural goods trade in China.

According to the main conclusions drawn from this article, the following Suggestions are put forward: Optimizing the structure of cultural industry and adjusting the structure and geographical 
distribution of cultural goods trade. Adjusting cultural trade and promote balanced development of core cultural goods. We should attach importance to the cultural geography and geography, and optimize the trade and regional structure of the core cultural goods. We also ought to use digital technology to develop high-end cultural industries. In recent years, China's online game, digital media products such as digital network technology as representative's emerging cultural goods export has been grown rapidly. They become the main driving force of cultural goods export growth, but the overall influence in the world is not strong.

\section{References}

[1] A. Marvasti: Journal of Cultural Economics, Vol. 18 (1994) No.2, p.135

[2] G. Schulze: Journal of Cultural Economics, Vol. 23 (1999) No.1, p.109

[3] B. Tadesse and R. White: Open Economics Review, Vol. 21 (2010) No.2, p.237 261

[4] R.X. Qu and L.L. Han: Social Sciences in Heilongjiang (2011) No.4, p.34 (In Chinese)

[5] A.C. Disdier, S. Tai, L. Fontagne and T. Mayer: Review of World Economics, Vol. 145 (2010) No.4, p.575

[6] S.Q. Zhou and Z.X. Lan: Journal of International Trade, (2013) No.1, p.117 (In Chinese)

[7] Information on https://comtrade.un.org

[8] Y. Liu, R.X. Qu and Y.P. Zeng: Journal of International Trade, (2013) No.11, p.72 (In Chinese)

[9] Information on http://www.geert-hof stede.com

[10] J.E. Anderson and E. Wincoop: American Economic Review, Vol. 93 (2003) No.1, p.170

[11]A. Tubadji, B.J. Osoba and P. Nijkamp: Journal of Cultural Economics, Vol. 39 (2015) No.3, p.277

[12]Qiang Chen: Advanced Econometrics and Stata Applications (Higher Education Press, China 2014) 